\title{
CECÍLIA MEIRELES E GENEVIEVE NAYLOR: FIGURAÇÕES DA CULTURA POPULAR NO CONTEXTO DA II GUERRA
}

\author{
Roniere Silva Menezes
}

RESUMO: Este trabalho visa a refletir sobre trabalhos realizados pela poetisa brasileira Cecília Meireles e pela fotógrafa norte-americana Genevieve Naylor durante o período da II Guerra Mundial. As duas vivenciaram o conflito internacional, mas vivenciaram também, nos anos iniciais da década de 1940, uma outra guerra: a guerra cotidiana das divisões sociais, do preconceito em relação aos negros. A fotógrafa e a poetisa estiveram envolvidas com o projeto denominado "Política da boa vizinhança". Cecília trabalhou, para o DIP, órgão do Governo Vargas, como editora da revista Travel in Brazil. Em 1941 viaja aos Estados Unidos para proferir palestras sobre cultura popular. Em crônicas e poemas trata da questão negra. Genevieve chega ao Brasil em 1941, permanecendo até 1942. Suas fotos ressaltam imagens relativas à cultura popular principalmente negra - e a convivências cotidianas. Os trabalhos das artistas ampliam as imagens do Brasil de meados do século XX.

PALAVRAS-CHAVE: literatura - fotografia - guerra - cultura afro-brasileira

ABSTRACT: This paper aims to reflect upon the work of the Brazilian poet Cecília Meireles and the North-American photographer Genevieve Naylor during the II World War. Both women experienced the international conflict, but they have also experienced other wars during the first years of the 1940s: the daily war of social hierarchies; racism. The photographer and the poet were part of the program known as "The Good Neighbor Policy". Meireles used to work as the editor of the journal Travel in Brazil for the DIP, an organ of Vargas's government. In 1941 she traveled to the United States to conduct lectures about popular culture. Meireles has also presented aspects of the Afro-Brazilian culture on poems and other texts. Genevieve came to Brazil in 1940 and stayed here

\footnotetext{
${ }^{1}$ Doutora em Estudos Literários pela Universidade Federal de Minas Gerais (2008).
} 
until 1942. Her photos show images related to the popular culture - especially Afro-Brazilian - and to the daily life. Both artists amplify the images of Brazil during the middle of the XX century.

KEYWORDS: literature - photography - war - afro-brazilian culture A lira, a lente e a Política da Boa Vizinhança

Este trabalho visa a refletir a respeito de produções da poetisa brasileira Cecília Meireles e da fotógrafa norte-americana Genevieve Naylor realizadas durante o período da II Guerra Mundial, mas focadas não no grande evento da guerra e, sim, no cotidiano popular brasileiro do período. As duas vivenciaram intensamente o conflito internacional, mas conheceram também, nos anos iniciais da década de 1940, uma outra guerra: a luta cotidiana de superação travada pelas classes populares do país, sobressaindo, nesse sentido, os desafios enfrentados pelas comunidades afro-brasileiras. As produções das artistas expressam seu posicionamento quanto a essa questão. A fotógrafa e a poetisa estiveram envolvidas com o projeto denominado "Política da boa vizinhança", levado adiante pelo presidente norte-americano Franklin Roosevelt, cuja proposta central seria a de promover uma maior integração entre os Estados Unidos, México e países da América do Sul. A operação intitulada "Política da Boa Vizinhança" foi fortalecida a partir de 1940. Além dos interesses econômicos e estratégicos pensando em defesa territorial durante a guerra -, a arte e a cultura tiveram papel central nesse projeto.

A criação poética de Cecília Meireles e as fotografias de Genevieve Naylor colocam em questão a força da cultura afro-brasileira nos anos iniciais da década de 1940. Elas instauram, por meio de uma "poética do arquivo", a desconstrução de coleções e arquivos oficiais. O trabalho das artistas revela-se como forma de resistência a discursos hegemônicos, como maneira de questionar a montagem de arquivos de linhagem política autoritária. Segundo Jacques Derrida:

$\mathrm{O}$ arquivo não trata do passado, ele trata do futuro. Seleciono violentamente o que considero que é preciso que se repita, que se guarde, que se repita no futuro. É um gesto de grande violência. $\mathrm{O}$ arquivista não é alguém que guarda. É alguém que destrói. (...). (DERRIDA. Pensar em não ver, p. 132). 
Além de denunciar a problemática racial dos negros brasileiros $\mathrm{e}$ norte-americanos, no período da Segunda Guerra Mundial, Cecília e Genevieve valorizam a potência inventiva, a força de trabalho, os encontros comunitários dessas populações.

Os caminhos de Cecília e Genevieve tocam-se de diversos modos. Por meio de nossa leitura, poesias e crônicas de uma podem roçar as fotografias da outra, dando-lhe novas nuanças; luzes, sombras, expressões presentes em imagens da norte-americana podem acentuar sentidos presentes na escrita da brasileira. As duas viveram no Rio de Janeiro dos anos iniciais da década de 1940 realizando atividades do campo artístico-cultural, procurando, entre outros propósitos estéticos, estabelecer novas percepções em relação à ideia de comunidade. As duas mulheres contribuíram para uma compreensão mais rica a respeito dos embates da época existentes, por exemplo, entre as forças da guerra, da ditadura Vargas e a criatividade popular brasileira. Elas se interessaram fortemente pela canção popular, pelo samba de morro. A linguagem musical permeia toda a criação de Cecília, como se pode notar nos desenhos e aquarelas que buscavam alcançar os gestos e ritmos de sambistas, capoeiristas, "baianas do carnaval"; na construção do verso poético e mesmo na composição das crônicas. A música faz-se presente não apenas nas imagens realistas de festas profanas ou religiosas captadas pelas lentes de Genevieve, mas nos movimentos, nas cadências, nos contrapontos entre claros e escuros estampados nas fotografias da norte-americana. Podemos pensar que Cecília realizou ótimos retratos com sua pena e Genevieve escreveu instigantes poemas com sua câmera.

Cecília e Genevieve estiveram presentes em Ouro Preto, na Semana Santa de 1942. No ano em que o Brasil declara guerra às potências do Eixo, Alemanha, Itália e Japão, as duas artistas foram ao interior de Minas em busca das formas barrocas de Aleijadinho, de Mestre Ataíde, da riqueza da cultura religiosa popular. Mas viram mais: viram fantasmas de outros tempos transitarem pelas ruas de pedra da cidade antiga. Foram tocadas pelas figuras de mulheres caladas, enlutadas, perdidas no tempo; pela miséria dos esquecidos pelo processo da modernidade que havia deixado para trás, inclusive, a antiga capital mineira. Elas observaram, assim como no Rio de Janeiro, a convivência inter-racial das chamadas pessoas do povo. Perceberam, nos traços da velha 
cidade, uma áspera resistência ao projeto de modernização que começava a avançar no país; na brisa das montanhas, pressentiram a sobrevivência de sonhos de liberdade cantados pelos poetas árcades, almejados por Tiradentes. ${ }^{2}$

Tentativas, mesmo frágeis, de se criar formas de diálogo, de afeto, de amizade, de respeito às diferenças ecoa nos textos e imagens analisados. Como sabemos, Cecília transmite, em suas crônicas e poesias, entre outros pontos, forte preocupação sobre o caráter efêmero, passageiro da vida; por isso mesmo percebemos, em seus textos, o desejo de que houvesse uma maior integração entre os homens. Genevieve - mesmo tendo sofrido acusações de ser espiã do governo dos Estados Unidos - pretendia, com suas fotografias mostrar aos norte-americanos a possibilidade da existência de uma maior convivência inter-racial. Tangendo as criações das artistas, nota-se a intenção de enfrentar o tempo presente, as causas centrais que marcavam a vida dos homens e mulheres daquele período histórico.

\section{Cecília Meireles}

Em 1933, Cecília organizou uma exposição, no salão Pró-Arte, no Rio de Janeiro, onde são mostrados, ao público, desenhos e aquarelas que criara, relativos a manifestações da cultura popular afro-brasileira. Em 1934, apresenta esses trabalhos em conferência realizada em Portugal denominada "Batuque, samba e macumba". O livro Batuque, samba e macumba: estudos de gesto e de ritmo (1926-1934), contendo imagens e textos explicativos da autora foi publicado apenas em 1983, pela FUNARTE, em tiragem limitada. A segunda edição, visando a um público mais amplo, saiu em 2003. No livro, a autora trata, por exemplo, do "cordão", nome vindo da corda que demarcava o espaço onde se situavam componentes de determinada agremiação de samba e era utilizada para favorecer a condução do grupo:

Chama-se a isso um "cordão", porque, para o isolar dos populares, vai uma corda circunscrevendo o grupo.

$\mathrm{Na}$ segunda-feira de carnaval, esse grupo invariavelmente passará pela Praça Onze, um dos sítios mais velhos da cidade (...). (MEIRELES, 2003, p. 53)

\footnotetext{
${ }^{2}$ Ainda não nos foi possível saber se existiu um provável encontro entre a poetisa e a fotógrafa em terras cariocas ou mineiras.
} 
Ao contrário de algumas cordas de isolamento atuais, utilizadas inclusive em carnavais, o "cordão" funcionava para proteger a agremiação sambista que recebe esse nome, indicando algo leve, movente, que contagia de alegria ao passar, imagem distante de outros espaços duros ou soturnos, também presentes na obra de Cecília.

Em Mar absoluto/Retrato natural, e Pistoia, cemitério militar brasileiro, Cecília escreve sobre a II Guerra vista sob o ponto de vista da intimidade feminina. Em diálogo com um olhar que enfatiza o "povo menor" (na perspectiva de Gilles Deleuze), como podemos notar em diversas figuras comuns captadas por meio do obturador da câmera de Genevieve, Cecília parece enxergar o mundo da guerra em conformidade com a percepção de criança presente em alguns de seus textos. Segundo Murilo Marcondes de Moura, a poetisa, quando menina, "observava o mundo adulto do assoalho da casa da avó". (MOURA, 2016, p. 248). Em Olhinhos de gato, a voz lírica escreve, lembrando a infância: "Ninguém vê que o tímido caracol e a ruiva formiga cumprem seu inexplicável destino”. (Cf. MEIRELES, 1986a, p. 8-9). Para Murilo Marcondes,

A resposta de Cecília Meireles à guerra é, por excelência, civil, já que formulada a partir da experiência privada e doméstica, e, por esse fato, é também, mais do que qualquer outra entre os nossos poetas, visceralmente pacifista. (MOURA, 2016, p. 248-249)

Em 1940, Cecília viaja aos Estados Unidos para proferir palestras sobre a cultura popular brasileira. No livro Poemas de viagens (1940-1964), aparecem poesias escritas sobre o país da América do Norte. Em diversas crônicas, publicadas inicialmente em jornais, a poetisa trata da bomba atômica, do desarmamento, do pacifismo, da questão negra, no Brasil e nos Estados Unidos.

Entre as crônicas, Cecília escreve sobre visita ao bairro do Harlem, a audição de cânticos de Spirituals, e tentativa de conhecer o líder religioso Father Divine. Cecília não conseguiu encontrá-lo; escreve, porém, sobre a “personagem”, entre desconfiada e reflexiva, a partir de leitura de revistas a que teve acesso. Para a viajante, o líder espiritual: "Quer a união das Américas, e um só idioma, para facilitar a união dos homens." Em seguida, ela escreve sobre os planos do "pai" que, mesmo sendo “divino", entende muito de economia, finanças e política: 
Tão longe vai a ideia de união das Américas, no desejo do Father Divine, que, além de unidas, pede que estejam sob o mesmo governo e a mesma constituição. Nesse ponto, sua concepção democrática é perturbada, e chega a afirmar que o "sistema ditatorial seria melhor que uma democracia, se a pessoa escolhida para dirigir fosse honesta, justa e correta". (MEIRELES, 1998, p. 34).

Cecília assinala que o pastor agia como se fosse guiado por extrema inocência, isso se realmente a figura portasse toda a "pureza de espírito que tanto exalta" - e que, afinal, bem pode ser que exista mesmo." (MEIRELES, 1998, p.34)

Em outra crônica, a autora relata ações desenvolvidas por mulheres dos Estados Unidos, durante a Segunda Guerra. Recorda o Emblema da Vitória que recebeu de uma associação feminina, simbolizando "todos os anelos da mulher norte-americana, defensora dos ideais democráticos”. (MEIRELES, 1998, p. 35). O distintivo visava valorizar pessoas que se destacavam a favor do panamericanismo. A crônica traz alguns problemas, acredito, relacionados a certa visão a respeito do lugar da mulher na sociedade. Mas, de modo geral, contribui para o debate sobre trabalhos realizados por mulheres em períodos de conflitos internacionais, no caso, sobre atividades de mulheres norte-americanas. Em certo momento do texto, Cecília nos apresenta sua percepção do projeto, por meio de um olhar perspicaz, lírico e utópico:

Isso é o que enternece: multiplicam-se aviões, submarinos, bombas, tanques de guerra e o número de mortos. Mas as mulheres americanas pensam na resistência, na defesa, na união de todas as mulheres de boa vontade (...).

Sem dúvida, os homens querem o mesmo: mas querem-nos aos berros, berros de canhão, de altos explosivos, berros de desespero, de sofrimento, de maldição. As mulheres falam com mais brandura, e, em lugar de armas assassinas, aqui estão com o seu broche índigo, branco, azul e ouro. Dizem as criaturas que o céu é dos mansos. As mulheres serão mais ouvidas, por falarem mais baixo; e a elas talvez se venha a dever um dia a construção do céu neste mundo de dores. (MEIRELES, 1998, p. 38)

Cumpre lembrar que Cecília trabalha, para o DIP - Departamento de Imprensa e Propaganda do Governo Vargas -, como editora da revista Travel in Brazil, escrita em Inglês e veiculada no exterior, nos anos de 1941 e 1942, com artigos sobre o país. Deve-se ressaltar que a revista Travel in Brazil, como outras publicações da época, 
passava por sério crivo de censura do DIP, inclusive quando apresentava fotografias, filmes e textos que tratavam da cultura afro-brasileira. Em troca de correspondências com Mário de Andrade, esse aspecto torna-se bastante evidente (Cf. MEIRELES, 1996). Cecília escreveu sobre o carnaval carioca para a Travel in Brazil, volume 1, número 2, de 1941. O texto foi ilustrado por diversas fotos, mas, estranhamente, a presença negra aparece pouco nas gravuras que ilustram a crônica.

Em 1942, Cecília viaja a Ouro Preto para realizar uma reportagem sobre a Semana Santa. O texto, onde a escritora apresenta finas observações a respeito das festividades religiosas ocorridas na cidade mineira, intitula-se "Holy Week in Ouro Preto". Foi publicado no volume 2, número 4, da revista Travel in Brazil, de 1942. As crônicas que Cecília escreveu sobre o Carnaval Carioca e sobre a Santa de Ouro Preto foram ilustradas, na revista Travel in Brazil por imagens de alguns fotógrafos. Infelizmente não foram estabelecidos diálogos entre os trabalhos de Cecília e Genevieve em algum livro, revista ou mesmo exposição, naquele período. Este ensaio, de certa forma, tenta recuperar esse desejo de aproximação que parece ter existido entre as próprias criações das autoras, que representaram, com engenho e arte, o Brasil do samba e do Barroco, no início da década de 1940.

Por sugestão de Juscelino Kubitschek, a crônica da viagem a Minas, escrita por Cecília, transforma-se em $O$ romanceiro da inconfidência, criação épica que trata da Inconfidência Mineira, mas onde afloram imagens de escravos, negros, negras, mulatos e mulatas das Gerais - figuras esquecidas nos versos árcades de Cláudio Manuel e Tomás Gonzaga. O livro é publicado em 1953. Na apresentação, escreve a autora:

(...) Vim com o modesto propósito jornalístico de descrever as comemorações de uma Semana Santa; porém os homens de outrora misturaram-se às figuras eternas dos andores; nas vozes dos cânticos e nas palavras sacras (...); diante dos nichos e dos Passos, brilhou o olhar de donas e donzelas, vestidas de roupas arcaicas, com seus perfis inatuais e seus nomes de ouras eras. $\mathrm{Na}$ procissão dos vivos caminhava uma procissão de fantasmas: pelas esquinas estavam rostos obscuros de furriéis, carapinas, boticários, sacristães, costureiras, escravos - e pelas sacadas debruçavam-se aias, crianças, como povo aéreo, a levitar sobre o peso e a densidade do cortejo que serpenteava pelas ladeiras. (MEIRELES. Romanceiro da Inconfidência, 1989, p. 13) 
Ao lado de imagens sobre figuras conhecidas da história mineira ligadas ao ciclo do ouro, aparecem, nos poemas de O Romanceiro da Inconfidência, figuras anônimas, referência a trabalhos de escravos, a "Chico Rei”. Em relação à temática negra, o livro traz longo poema sobre Chica da Silva. No "Romance VII ou do negro das Catas", podemos ler:

\author{
Já se ouve cantar o negro. \\ Chora neblina, a alvorada. \\ Pedra miúda não vale: \\ Liberdade é pedra grada... \\ (A terra toda mexida, \\ A água toda revirada... \\ Deus do céu, como é possível \\ Penar tanto e não ter nada!) \\ (MEIRELES, 1989, p. 60)
}

O canto negro invade os versos que contam a história da Inconfidência Mineira, ou da Conjuração Mineira. No poema acima, notamos a força da palavra "guerra" que se desloca de altos acontecimentos mundiais para a batalha diária dos que penam muito para receber muito pouco. A voz poética também nos oferece elementos que demonstram a positividade da cultura negra. No livro são encenadas, por meio de manifestações religiosas ligadas a cantos, danças, tambores, diferentes formas de lutas pela liberdade. No Romance VIII ou do Chico-rei, Cecília descreve a Festa do Rosário, onde se comemora a abolição da escravatura:

Olha a festa armada:

é vermelha e azul.

Canta e dança agora, meu povo,

livres somos todos!

Louvada a Virgem do Rosário,

vestida de luz.

(MEIRELES, p. 63)

Jacques Rancière contribui com nossa discussão relativa à guerra também travada por artistas, poetas, cineastas para trazerem à tona imagens, sons, gestos que geralmente permanecem nas margens, em instâncias de pouca visibilidade. De acordo com o filósofo,

A expressão "política da literatura" implica (...) que a literatura intervém enquanto literatura na decupagem dos espaços e dos tempos, do visível e do invisível, da palavra e do ruído. Ela intervém dentro da relação entre as práticas das formas de 
visibilidade e dos modos de dizer que recortam um ou vários mundos comuns. (RANCIÈRE, 2007, p. 3)

\section{Genevieve Naylor}

Genevieve Naylor conhecia bem a problemática racial norte-americana. Vivenciou, em seu país, ações de discriminação contra negros, autorizadas institucionalmente por leis do Estado. Percebia, ao seu redor, atitudes endossadas pelas linhas que dividiam espaços possíveis ou não de serem ocupados pelos negros, a chamada color line. Genevieve inicia seus trabalhos, como fotógrafa, em um programa social em Nova York, em 1937, quando tinha 22 anos. Ela foi contratada pelo Work Progress Administration para documentar o cotidiano da vida de negros no bairro do Harlem. O projeto era ligado ao New Deal e tinha entre os seus propósitos incentivar o trabalho de artistas negros em peças teatrais de caráter comunitário.

Genevieve chega ao Brasil em outubro de 1940, permanecendo até em agosto de 1942. Suas fotografias, no país, apresentam, entre outras, imagens ligadas à cultura popular, em especial a afro-brasileira, a metrópoles como Rio de Janeiro e São Paulo, a cidades históricas mineiras e ao Vale do Rio São Francisco. Deve-se salientar que, neste ensaio, estamos nos utilizando, para análise, de fotografias presentes no livro Genevieve Naylor: uma fotógrafa norte-americana no Brasil/ an american fhotographer in Brazil (1940-1942) e também das setenta e seis fotografias - algumas parecem que inéditas presentes em exposição permanente da artista, no Acervo de Escritores Mineiros da UFMG, Campus Pampulha, em Belo Horizonte. Genevieve fotografou o carnaval do Rio de Janeiro, em 1941, e a Semana Santa de Ouro Preto, em 1942 - quando assessorou Orson Welles nas filmagens que o cineasta realizava da procissão religiosa que acontecia na cidade, para o inacabado filme It's all true. Segundo Ana Maria Mauad:

Assim que chegou ao Rio de Janeiro, Naylor recebeu instruções claras do DIP sobre o que deveria fotografar. O documento do Departamento de Imprensa e Propaganda (DIP) que a autorizava trabalhar no Brasil indicava que a sua função estava restrita fotografar os pontos turísticos da Capital Federal. A fotógrafa precisaria valorizar alguns temas, dentre os quais: arquitetura moderna (principalmente prédios governamentais); casas dos bairros nobres, como Lagoa, Gávea e Ipanema; interior de casas importantes e elegantes, no bairro do Flamengo; os domingos 
de sol nas praias de Copacabana e Ipanema; as corridas de cavalo no Jockey Club, os veleiros e iates na baía de Guanabara, o comércio exclusivo da Rua do Ouvidor e as obras de caridade da Primeira Dama, Dona Darcy Vargas. (Cf. MAUAD, 2014, p. 145-146.)

Entre os temas retratados por Genevieve Naylor, podem ser destacadas imagens do Rio de Janeiro que, segundo Mauad, apresenta-se como "espaço no qual a experiência multicultural brasileira se impõe pelo olhar da fotógrafa." (MAUAD, 2014, p. 146). Convivências inter-raciais, encontros comunitários, tudo recebe tratamento cuidadoso nas lentes de Genevieve. Deve-se ressaltar que as fotografias trazem também figuras de vendedores e vendedoras ambulantes, pescadores, funileiro, amolador de faca, estivadores, feirantes, entregadores, operários urbanos, soldados, artistas de teatro de revista, artistas de rua, moradores de cortiço: pessoas comuns ganham destaque na série. Boa parte não são negros, mas pobres trabalhadores em simples ofícios. Essas fotografias ganham maior relevância pois são apresentadas, sem nenhum sentido hierárquico, ao lado de outras que retratam pessoas da alta sociedade, políticos, poetas, intelectuais, paisagens, edifícios.

Os estudos de gesto e ritmo empreendidos por Cecília aguçam sua atenção para as sutilezas de expressões afro-brasileiras ligados ao samba, ao batuque e à macumba, movimentos que ela almeja fixar, por meio de desenhos e aquarelas. As gingas, as cadências, a simplicidade sublime de negros e negras aparecem também nas fotografias de Genevieve relativas ao carnaval. Em artigo intitulado "A última catedral", publicado no jornal A manhã, em 19 de outubro de 1941, Vinicius de Moraes escreve sobre Genevieve:

Genevieve parece ter saído de uma história de Robin-Hood, com seu arzinho de jovem pajem, sua elegância bem colorida, uma pena sempre atrevidamente espetada no chapéu. Nada escapa, no entanto, à maquinazinha dessa enfeitiçada. Perto dela não há momento fotográfico que passe sem cair naquela arapuca bem armada. Genevieve dá um pulinho e a vida ali ficou batendo asa na sua chapa impressionada.

(MORAES, 1941)

Sobre as relações interculturais e interartísticas propiciadas pelo projeto da "Política da Boa Vizinhança", não podemos nos esquecer dos estreitos laços criados 
entre viajantes estrangeiros e o contista mineiro Aníbal Machado. Vale a pena citarmos trecho de texto do autor a respeito da produção de Genevieve em terras brasileiras:

(...) Os assuntos populares, humildes, os tais elementos essenciais que compõem a fisionomia do nosso povo são captados, pela fotógrafa da Boa Vizinhança. Mas sua maneira de fixar a realidade nada tem de monumental. (...) Um país - o Brasil - captado então na sua força real: assim, no carnaval, a alegria é antes uma vibração convulsiva da tristeza que procura atordoar-se... como se estivesse procurando o resumo etnográfico. Importante o olhar, a percepção das imagens simples, que permite a recuperação dos tempos históricos acomodados no cotidiano, mas que resgata a vida de cada um em sua profundidade e intensidade. Não raro surge uma imagem agônica, áspera porém silenciosa, sempre densa. "Nada de cachoeiras...". (MACHADO, 1941)

Em relação à questão etnográfica acentuada por Aníbal Machado, revela-se, como vimos dizendo, o explícito interesse de Genevieve pelo lugar ocupado pelo negro no país, fato que provoca atritos com autoridades ligadas ao governo brasileiro e norte-americano. $\mathrm{O}$ interesse, nesse sentido, era que a paisagem brasileira revelasse, além de exotismos, cores e modos mais próximos ao padrão europeu ou ao American Way of Life, mas esses signos eram frontalmente postos em questão por um projeto artístico que colocava em primeiro plano o que se queria recalcar.

Sendo às vezes proibidas ou impedidas de se manifestarem em sua inteireza por conta de perseguições existentes durante a Era Vargas -, expressões ligadas ao samba, ao batuque e à capoeira ligam-se a performances corporais que transmitem a tradição de práticas culturais (Cf. OLIVEIRA. A repressão policial às religiões de matriz afro-brasileiras no Estado Novo (1937-1945). A memória do corpo é bastante retratada na obra de Genevieve. Para Ana Maria Mauad: "Destaca-se nas imagens de Naylor, o protagonismo da população negra no carnaval brasileiro configurado como performance visual e política marcada pelo domínio do corpo em movimento e pela ocupação dos espaços públicos da cidade.” (MAUAD, 2014, p. 149). Deve-se salientar que, de forma bastante paradoxal, a partir do Estado Novo, o candomblé, o samba e a capoeira - normalmente vistos com desconfianças por forças estatais - passam a ser utilizados como símbolos do projeto nacionalista de Getúlio Vargas, por meio de um 
processo de descriminalização da cultura de origem africana. A intenção era a construção de um projeto de homogeneização cultural no país. (Cf. VIANA, 1995)

Jacques Rancière desenvolve argumentos que favorecem nossas reflexões. Para o filósofo, o diferencial de uma política estabelecida pelo viés da literatura - termo que, neste ensaio, pode ser entendido de forma expandida, englobando a arte fotográfica seria o de opor-se à encenação verborrágica do modelo "democrático" oficial. Este, "voluntariamente se constitui pelo enviesamento das palavras, das frases e da retórica dominante" (RANCIÈRE, 2007, p. 20). Dessa forma estaria aberto o caminho para se auscultar outras vozes. Segundo o pensador, na configuração de uma "política da literatura" seria importante:

(...) sair da cena da palavra veiculada por vozes sonoras para decifrar os testemunhos que a sociedade por si mesma oferece à leitura, para desenterrar aqueles que ela, sem querer nem saber, remove para zonas marginais obscuras. À cena ruidosa dos oradores opõe-se a viagem aos subterrâneos que resguardam a verdade oculta. (RANCIÈRE, 2007, p. 20-21)

Percebe-se uma leveza ao mesmo tempo delicada e questionadora nas produções Genevieve. Por isso elas são poéticas, trazem o tom feminino, o que aproxima suas representações da lírica moderna de Cecília. As fotografias endossam a potência do "povo menor". Distante dos barulhos de canhões e metralhadoras, uma sonoridade ancestral parece carregar o germe de novas formas existenciais, ainda que outras guerras - as da batalha diária pela sobrevivência e pela afirmação da própria raça e cultura sejam encenadas nas performances captadas por meio de filtros fotográficos. A pulsão negra, o corpo em luta contra amarras sociais, as síncopes do tamborim, o canto coletivo interferem na "modelagem" das fotografias que trazem a assinatura de Genevieve Naylor.

Nas produções de Genevieve realizadas em Minas Gerais, mesclam-se imagens do Barroco e do moderno. Nelas, vemos impressas a vida cotidiana de Ouro Preto, Congonhas do Campo, São João del Rey, mas podemos observar também imagens da moderna Belo Horizonte, onde Juscelino Kubitschek é fotografado, com a mulher, Sarah Kubitschek, em uma recepção no Cassino da Pampulha. Assim como nos trabalhos do Rio de Janeiro, Genevieve exerce suas atividades, em Minas, com imenso talento, destacando-se os ambientes abertos, onde sabe medir, como poucos, 
intensidades de luz e sombra visando realçar seu objeto. Ao contrário do ambiente de luxo da Pampulha, as ruas de pequenas cidades, vilarejos e ambientes rurais lançam, aos nossos olhos, o outro lado do processo de modernização brasileira que então se iniciava; o outro lado do conflito internacional, profundamente ligado ao capitalismo modernizante.

As fotos do interior brasileiro - assim como as cariocas - apresentam uma proximidade, mesmo uma cumplicidade da artista estrangeira com pessoas humildes. Nesse sentido, devemos notar que o aspecto multicultural e plurirracial do país, vislumbrado por Naylor no Rio de Janeiro também ressoa em suas produções realizadas em Minas. Os figurantes da dinâmica social passam a ocupar o centro da cena artística criada pela viajante estrangeira; miram a câmera como se olhassem para uma fotógrafa que fosse "de casa"; são flagrados em atividades do dia-a-dia ou posam para a norte-americana com bastante espontaneidade. Entre essas figuras, aparecem a lavadeira, o violeiro, o acordeonista, vaqueiros, barqueiros, mulheres peneirando areia ou carregando água, criança trabalhando na bateia, famílias sertanejas, tipos populares. Todos viram atores e atrizes de um palco comum. Os rostos dos famosos "doidinhos" que transitam pela obra de Guimarães Rosa podem ser vistos de forma bem concreta na obra de Genevieve. A fotógrafa parece querer mostrar a singeleza e a beleza da vida pulsando em diferentes matizes; almeja, com sua sensibilidade e argúcia ao lidar com a máquina, ser a nossa guia; o seu olhar passa a ser o nosso próprio olhar a transitar por cidades, periferias e sertões, aproximando-nos do outro, desejando despertar nosso afeto para aquelas existências miúdas, precárias, muitas vezes bem distantes de nosso convívio habitual.

Os planos - entendidos como distâncias -, as alturas e os ângulos laterais ligam-se aos enquadramentos almejados por Genevieve, por meio de sua objetiva. Esses elementos estabelecem relações com os diversos lugares discursivos construídos pelo sujeito lírico e pelo foco narrativo presentes no tecido literário de Cecília. Esse aspecto revela-se essencial na aproximação entre fotografia e literatura e pode ser tomado como espécie de educação do olhar, da sensibilidade, mostrando-nos diferentes formas de lidar com um mesmo assunto, um mesmo objeto. 
Na crônica de Cecília Meireles intitulada "Se eu fosse pintor", a autora trata de diversos planos de uma descrição. Em forma de metalinguagem, o olhar ficcional inicia seu relato a partir de um pequeno e próximo jardim e segue apresentando diversos quadros até a vista atingir a paisagem distante. A narrativa funciona como exemplo de diálogo passível de ser estabelecido entre literatura, pintura fotografia e cinema. Podemos pensar que as modulações de perspectivas estéticas podem ainda contribuir com a construção de posicionamentos políticos mais democráticos, abertos a diferentes opiniões e gostos (Cf. MEIRELES, 1976).

Quando a norte-americana fotografa a Semana Santa de Ouro Preto, oferece-nos um cortejo de figuras que parecem vir de um mundo passado, como fantasmas - assim como escreve Cecília Meireles sobre o mesmo evento -, a deslocar as concepções mais homogêneas sobre um país voltado ao futuro. Além dos marcos da fé popular, dos devotos em procissão pela cidade barroca de Ouro Preto, Genevieve mostra-nos o entorno da cerimônia: atividades em pequenos comércios, encontros de populares, flagelados, músicos negros pedintes. A artista também realizou fotografias em Congonhas do Campo. Nesse material, podemos observar uma multidão de romeiros desfilando sob os olhares dos profetas. Tanto nas imagens do Rio de Janeiro quanto nas de Minas, por exemplo, nota-se o interesse da artista em criar uma coleção fotografias onde pessoas negras, brancas, mulatas, de diversas idades, parecem conviver de modo harmônico e respeitoso, experiência mais difícil de ser vislumbrada nos Estados Unidos daquele período, onde a segregação racial imperava. Não podemos, todavia, nos esquecer de que o preconceito racial sempre esteve também presente, às vezes de modo camuflado, no Brasil.

De acordo com Roland Barthes, "Em um primeiro tempo, a Fotografia, para surpreender, fotografa o notável; mas logo, por uma inversão conhecida, ela decreta notável aquilo que ela fotografa.” (BARTHES, 1984, p. 57). Ainda, de acordo com o pensador, "a Fotografia é subversiva, não quando aterroriza, perturba ou mesmo estigmatiza, mas quando é pensativa." (BARTHES, 1984, p. 62).

Jacques Rancière chama-nos a atenção para a relação entre transformações existentes no campo estético, técnico e histórico, afirmando que a literatura deu o primeiro passo em direção à vida das pessoas ordinárias. Essa questão contribui para 
estreitar os pontos de contato - obviamente com todas as diferenças - que acreditamos existir entre a produção de Cecília e de Genevieve. Para Rancière:

A revolução técnica vem depois da revolução estética. Mas a revolução estética é antes de tudo a gloria do qualquer um - que é pictural e literária, antes de ser fotográfica ou cinematográfica.

Acrescentemos que ela pertence à ciência do escritor antes de pertencer à do historiador. Não foram o cinema e a fotografia que determinaram os temas e os modos de focalização da "nova história". São a nova ciência histórica e as artes da reprodução mecânica que se inscrevem na mesma lógica da revolução estética. Passar dos grandes acontecimentos e personagens à vida dos anônimos, identificar os sintomas de uma época, sociedade ou civilização nos detalhes ínfimos da vida ordinária, explicar a superfície pelas camadas subterrâneas e reconstituir mundos a partir de seus vestígios, é um programa literário, antes de ser científico. (RANCIËRE, 2009, p. 48-49.).

A comparação entre os trabalhos de Cecília e Genevieve auxilia-nos a pensar em possíveis diálogos que poderiam existir entre ética, estética, técnica e política, alterando, desse modo, o foco da macro "Política da boa vizinhança" para a micro política cotidiana. Criações artísticas, olhares, escutas, reflexões são realizadas nesse trajeto em busca de um mundo perdido, arcaico, primitivo que pudesse, talvez, contribuir para outras formulações da ideia de modernidade, distantes dos embates relativos ao ódio racial e à guerra. Rancière, pensando nos diálogos entre arte e política, acentua:

A atividade política reconfigura a partilha do sensível: ela introduz no cenário comum objetos e sujeitos novos; ela torna visível o que estava invisível; ela torna audíveis como seres dotados de palavra aqueles que apenas eram ouvidos como animais ruidosos. (Cf. RANCIÈRE, 2007, p. 2)

Genevieve Naylor passou por sérios problemas no Brasil por desafiar as regras sobre o que deveria e poderia ser fotografado: um bonito, pujante e hospitaleiro país tropical. Equipamentos de trabalho de Naylor foram apreendidos, houve perseguições a ela e ao marido, Misha Reznikoff, artista plástico que ajudou a criar o MAM-Rio. A artista teve dificuldades no processo de liberação de fotos para exposição que realizara no MoMa, em Nova York, aberta ao público entre os dias 27 de janeiro e 28 de fevereiro de 1943, intitulada Rostos e lugares do Brasil, onde foram apresentadas 50 fotografias tiradas durante sua estada no país. Em 1990, foi publicado, nos Estados 
Unidos, livro com as fotos brasileiras da artista. No Brasil, o livro Genevieve Naylor: uma fotógrafa norte-americana no Brasil (1940-1942) saiu em 2013.

\section{Literatura e fotografia como descolecionismo}

A percepção da guerra cotidiana levada adiante por pessoas comuns brasileiras, enfatizando-se as lutas e o caráter inventivo dos afro-brasileiros, no início dos anos 1940, amplia os sentidos da II guerra mundial, demonstrando o valor do trabalho artístico-literário para a desconstrução de arquivos oficiais e elaboração de arquivos abertos a outras formas, menores, de encenação política. As "coleções", os arquivos elaborados por Cecília e Genevieve relacionam-se ao conceito de "descolecionismo" estabelecido pela pesquisadora Ivette Sánchez. (Cf. SÁNCHES. Coleccionismo y literatura).

O "descolecionismo" liga-se à dessacralização das coleções e dos arquivos oficiais, hegemônicos, como os que hierarquizam e estabelecem fronteiras rígidas entre formas de arte, cultura, saber e visam, ao se formarem, impedir uma compreensão mais ampla de símbolos e objetos nacionais, por meio da valorização e exibição de determinados conteúdos relativos, por exemplo, à imagem que se almeja fixar na memória do país e serem exibidos no exterior. Os trabalhos da poetisa e fotógrafa podem ser vistos como coleções abertas à diferença, ao imprevisto, capazes de provocar o deslocamento dos sentidos habituais. Daí, o forte sentido artístico, ético e político de suas obras.

\section{REFERÊNCIAS BIBLIOGRÁFICAS:}

BARTHES, Roland. A câmara clara: nota sobre a fotografia. GUIMARÃES, Júlio Castañon (Trad.). 7 . impressão. Rio de Janeiro: Ed. Nova Fronteira, 1984.

DERRIDA, Jacques. Rastro e arquivo, imagem e arte. Diálogo. in Pensar em não ver: escritos sobre as artes do visível (1979-2004). MORAES, Marcelo Jacques (Trad.). MICHAUD, Ginette; MASÓ, Joana, BASSAS, Javier (Org.). Florianópolis: Ed. da UFSC, 2012, p. 91-144.

ERMAKOFF, George. Genevieve Naylor: uma fotógrafa norte-americana no Brasil/ An american photographer in Brazil (1940-1942). Rio de Janeiro: G. Ermakoff, 2013.

MACHADO, Aníbal. Nada de cachoeiras. Diário de notícias. Rio de Janeiro: 28 de janeiro de 1941.

MAUAD, A. M. Fotografia e a cultura política nos tempos da política da Boa Vizinhança. Anais do Museu Paulista, vol. 22, núm. 1, enero-junio, 2014, pp. 133-159. 
Universidade de São Paulo. São Paulo, Brasil. Disponível em: http://www.redalyc.org/articulo.oa?id=27332475005

MEIRELES, Cecília. Batuque, samba e macumba: estudos de gesto e de ritmo 1926-1934. 2a . ed. São Paulo: Martins Fontes, 2003.

MEIRELES, Cecília. Cecília e Mário. Rio de Janeiro: Nova Fronteira, 1996.

MEIRELES, Cecília. Crônicas de viagem 1 (Obra em prosa). Apresentação e planejamento editorial de Leodegário A. de Azevedo Filho. Rio de Janeiro: Editora Nova Fronteira, 1998.

MEIRELES, Cecília. Ilusões do mundo. Rio de Janeiro: Nova Aguilar, 1976.

MEIRELES, Cecília. Olhinhos de gato. São Paulo: Ed. Moderna, 1986a.

MEIRELES, Cecília. Poesia completa. SECCHIN, Antonio Carlos (Org.). Rio de Janeiro: Nova Fronteira, 2001.

MEIRELES, Cecília. Romanceiro da Inconfidência. $6^{\mathrm{a}}$ ed. Rio de Janeiro: Nova Fronteira, 1989.

MEIRELES, Cecília (Org). Travel in Brazil. Rio de Janeiro: Departament of Press and Propaganda, volume 1, número 2, de 1941.

MEIRELES, Cecília (Org). Travel in Brazil. Rio de Janeiro: Departament of Press and Propaganda, volume 1, número 4, de 1942.

MOURA, Murilo Marcondes de Moura. O mundo sitiado: a poesia brasileira e a Segunda Guerra Mundial. São Paulo: Editora 34, 2016.

MORAES, Vinicius de. A Última Catedral. A manhã. Rio de janeiro, 19 de outubro de 1941.

OLIVEIRA, Nathália Fernandes de. A repressão policial às religiões de matriz afro-brasileiras no Estado Novo (1937-1945). Dissertação de mestrado. Niterói, RJ: Programa de Pós-graduação em História Social da Universidade Federal Fluminense, 2015.

RANCIÉRE, Jacques. A partilha do sensivel: estética e política. NETTO, Mônica Costa (Trad.). 2a . ed. 2009. São Paulo: Exo Experimental org.; Editora 34.

RANCIÈRE, Jacques. Política da literatura. CAPISTRANO, Renato Pardal (Tradução livre de "Politique de la littérature"). In: RANCIÈRE, Jacques. Politique de la littérature. Paris: Éditions Galilée, 2007, p. 11-40.

SÁNCHES, Yvette. Coleccionismo y literatura. Madrid: Ediciones Cátedra, 1999.

VIANNA, Hermano. O mistério do samba. Rio de Janeiro: Jorge Zahar, 1995.

Recebido em 17/12/2019. Aceito em 19/12/2019. 